\title{
Benchmarking the performance of hydrostatic pumps
}

\author{
Robin Mommers, Peter Achten, Jasper Achten, and Jeroen Potma \\ Innas BV, Breda, The Netherlands \\ E-mail: rmommers@innas.com, pachten@innas.com
}

\begin{abstract}
In search for sustainable and clean solutions, the hydraulic industry is forced to develop more efficient alternatives to traditional systems. For mobile applications, battery driven machines are becoming an essential solution. But, electric driven hydraulic systems set completely different demands than classical systems. Since batteries are expensive and bulky, it is no longer acceptable that the majority of the battery stored energy is lost in the hydraulic system.

One of the promising solutions for efficiency increase is the application of electrohydraulic actuators (EHAs). Aside from all the inherent control advantages, EHAs deliver energy to each load on demand. This makes them much more efficient than current valve controlled systems, at least in principle.

In practice, EHAs require both low and high-speed operation of pumps. Almost all hydrostatic pumps have high friction losses, strong wear and often also high volumetric losses at speeds below $500 \mathrm{rpm}$. Additionally, it is obvious that the pumps must have the highest efficiency possible.

Given these constraints and demands it is understandable that information is needed about the performance of pumps and motors. In the past years, Innas has measured and tested several positive displacement machines and published a comprehensive report about these measurements. This paper will analyse the outcome of the test results, with a special focus on the application in EHAs.
\end{abstract}

Keywords: pumps, performance, benchmark, efficiency, electro-hydraulic actuators

\section{Introduction}

Energy efficiency has become one of the most important topics for the hydraulic industry. The clear trend towards sustainable and clean solutions forces companies to develop more efficient alternatives to traditional systems. For mobile applications, battery driven (i.e. engine-less) machines are becoming an essential solution. According to the European Union "the objective is to progressively reduce the pollutant emissions and to phase out equipment with the most polluting engines" [1].

But, electric driven systems set completely different demands than classical systems. Since batteries are expensive and bulky, it is no longer acceptable that the majority of the battery stored energy is lost in the hydraulic system. Energy efficiency is no longer a question of fuel cost, but of battery costs i.e. initial investment costs.

One of the promising solutions for increasing efficiency is the application of electro-hydraulic actuators (EHAs). The basic concept of a linear electro-hydraulic actuator is shown in fig. 1. A variable speed electric motor is coupled directly to a constant displacement pump. The hydraulic flow generated by rotation of the pump is directed to a load, which in this case is a cylinder. To ensure that flow reaches the correct side of the cylinder, several auxiliaries can be used. A large number of recent studies has focussed on designing such auxiliary circuits to optimize efficiency, enable energy regeneration, and overcome problems related to the asymmetrical nature of standard single rod cylinders (for example [2-4]).

Control of the velocity at the load side of EHAs, like the cylinder shown in fig. 1, is achieved by controlling the speed of the electric motor. In practice, this means that EHAs require both low speed and high speed operation of pumps. The high speed capability corresponds with the demand for smaller and more efficient electric motors. On the other hand, the low speed capability is needed to achieve low load velocities. However, almost all hydrostatic 


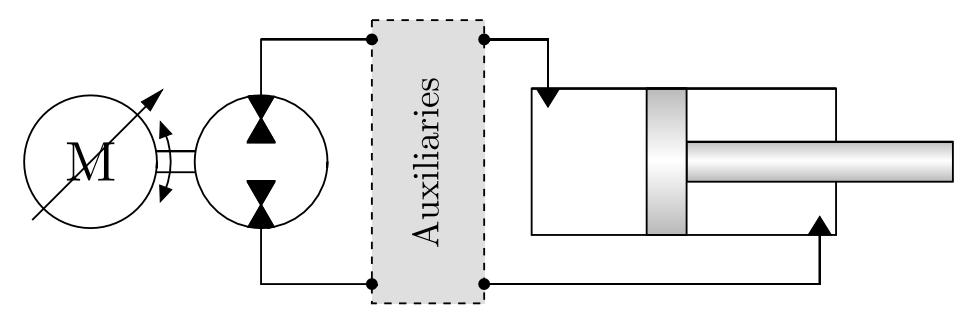

Figure 1: Simplified schematic of the basic concept of electro-hydraulic actuators (EHAs).

pumps have high friction losses, strong wear and often also high volumetric losses at speeds below $500 \mathrm{rpm}$. While there have been efforts to work around these minimum speed limitations of pumps, they typically depend on introducing new throttling losses via a variable leakage path $[5,6]$.

It is known, that there are almost no pumps available that meet both the high and low speed demands that are required for application in EHAs [7]. However, little to no information about the performance of pumps is available. Given these new constraints and demands it is understandable that this information is needed. In the past years, Innas has measured and tested several pumps and motors and published a comprehensive report about these measurements [8]. The report will be a living document, with new editions being published as soon as new pump (and motor) data will become available. In this paper, the outcome of the test results is analysed, with a special focus on the application in EHAs.

\section{Tested devices}

For the current study, five different hydrostatic devices were benchmarked: three piston pumps, and two gear pumps. Table 1 shows an overview of some of the key specifications of these devices. The piston-type units have a number of pistons $(z)$ ranging from 7 to 24 . From a physical point of view, the number of pistons in a piston-type machine is similar to the number of teeth in a gear pump. The geometric displacement volume, $V_{g}$, of each of the devices has been derived from volumetric measurements [9], and ranges from 23.7 to $32.7 \mathrm{cc}$ per revolution. The volume ratio $r_{V}$ describes the ratio between the amount of dead volume per piston, $V_{\min }$, and displacement volume per revolution, as described in eq. (1).

$$
r_{V}=\frac{z V_{\min }}{V_{g}}
$$

The value of $r_{V}$ shown in tab. 1 has been derived from a combination of drawings and geometrical measurements of the devices. The maximum pressure and speed limitations, $p_{\max }$ and $n_{\max }$ respectively, are provided by the manufacturers of the devices.

The derived geometric displacement volume $V_{g}$ is a scale for the size of the device. To operate a larger pump, more torque is required. In the case of EHAs, this means that a larger electric motor is needed. However, the movement of the cylinder in EHAs depends on the flow rate, which is the product of pump size and speed. In practice, the electric motor will almost always have a higher speed limitation than the pump. This means that a higher maximum pump speed will result in a larger maximum flow rate without the need to increase the size of the electric motor.

Table 1: Overview of the specifications of the tested hydrostatic pumps.

\begin{tabular}{llccccc}
\hline Pump name & Type & $z$ & $V_{g}[\mathbf{c c}]$ & $r_{V}$ & $p_{\max }[\mathbf{b a r}]$ & $n_{\max }$ [rpm] \\
\hline Rexroth A4FO28 & Axial slipper & 9 & 27.87 & 0.78 & 400 & 3750 \\
Moog RKP32 & Radial slipper & 7 & 32.66 & 0.08 & 350 & 2750 \\
Eckerle EIPH3-025 & Internal gear & 13 & 24.31 & 0.17 & 330 & 3200 \\
Marzocchi ELI2-D-25.7 & External gear & 7 & 25.41 & 0.00 & 210 & 3000 \\
Innas FC24 & Floating cup & 24 & 23.65 & 0.85 & 500 & 5000 \\
\hline
\end{tabular}

\section{Measurement description}

Each of the devices was benchmarked on the test bench at Innas BV [10]. This hydraulic test bench can operate pumps and motors at speeds ranging from $5000 \mathrm{rpm}$ to less than $0.01 \mathrm{rpm}$, by using two different actuators. The 
first actuator is a large electric motor, which is able to rotate the test device at any speed between 10 and $5000 \mathrm{rpm}$. This actuator is used to execute standard performance measurements in accordance with ISO4409:2019 [11].

The second actuator consists of a combination of a linear actuator and a sprocket, and is able to rotate the test device consistently at speeds from around 1 to less than $0.01 \mathrm{rpm}$. These extremely low-speed measurements provide useful information about the starting conditions of the different machines, which is very relevant for the use of these pumps and motors in EHAs. One of the benefits of EHAs is that the cylinder velocity can be controlled by the speed of the electric motor. In a typical load scenario, this means frequently switching between extraction and subtraction of the cylinder. This requires the pump to decelerate to a standstill and accelerate again.

The performance of each of the pumps was measured at a range of different discharge pressures. For the sake of conciseness, the following only shows the results of these measurements at a discharge pressure of 200 bar. The performance at the other pressure levels, as well as a more comprehensive description of the test bench, including pictures of the setup, hydraulic circuits, and sensor information, can be found in the full report [8].

\section{Electric motor sizing}

Before looking at any of the traditional results of the measured pumps, we want to be able to compare the devices when applied in an EHA. This will be done by looking at the relation between torque and flow rate. The electric motor delivers torque to the pump shaft in order to control the flow rate to the load. This flow rate can therefore be seen as the required output of the pump. The amount of torque required to achieve this flow rate, will correspond to the size of the electric motor: less torque generally means a smaller motor.

Figure 2 shows the measured torque on the pump shaft as a function of the discharge flow rate, at a discharge pressure of 200 bar. Each of the marked points is a measured operating speed. Due to the different pump sizes, the output flow rate and the torque varies for the different machines. This figure shows that the Moog, Eckerle, and Marzocchi pumps have a similar range of operation, with a maximum flow rate of about $75 \mathrm{lpm}$. To obtain this flow rate, the Eckerle only requires $85 \mathrm{Nm}$. On the other hand, the Moog pump needs an electric motor that can deliver a torque of $113 \mathrm{Nm}$, due to the difference in pump size. In other words, to obtain a flow of $75 \mathrm{lpm}$ at 200 bar, a system with the Moog pump would need an electric motor that is roughly $40 \%$ larger.

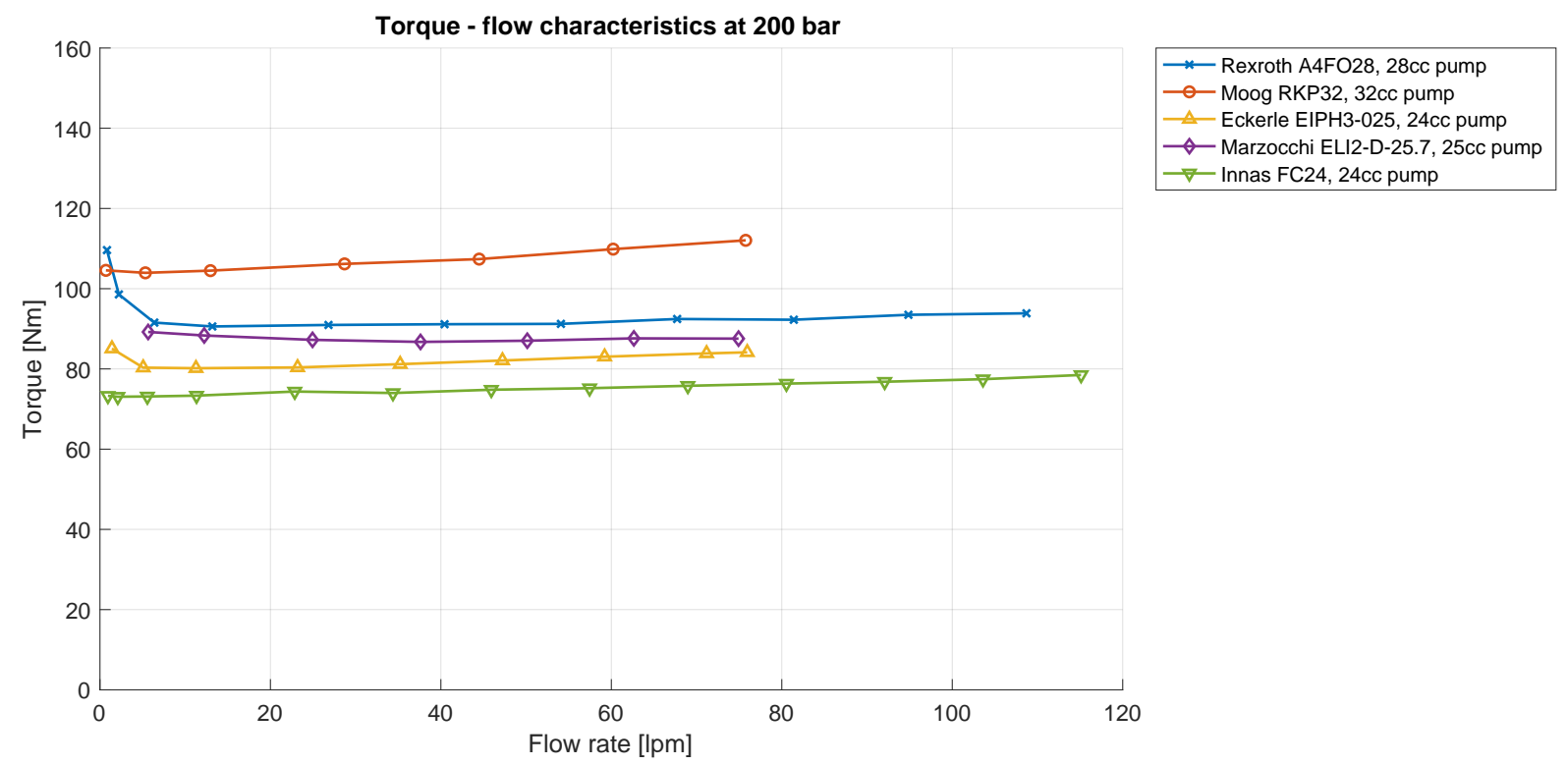

Figure 2: Measured torque as a function of the measured discharge flow rate, at a discharge pressure of 200 bar. Less torque means smaller electric motor.

The Rexroth and the Innas pump have a much higher maximum flow rate than the three other pumps. Suppose we want to design an EHA with a maximum output flow rate of $100 \mathrm{lpm}$ at 200 bar. Since the maximum flow rate of the $27.9 \mathrm{cc}$ Rexroth is roughly $110 \mathrm{lpm}$, we could settle for a pump that is $10 \%$ smaller than the tested unit: $25.4 \mathrm{cc}$. Furthermore, the torque of this smaller Rexroth pump is also expected to decrease with $10 \%$, from 94 to $85 \mathrm{Nm}$. If we assume that the performance of these devices scales proportionally with the size of the pump, the torques and flow rates shown in fig. 2 scale equally. Figure 3 shows these scaled torques and flow rates of the five pumps. 
From fig. 3, it is found that there is a large difference between the torque requirements of the tested devices when implemented in a $100 \mathrm{lpm}$ EHA at a discharge pressure of $200 \mathrm{bar}$. The (scaled) Innas pump is expected to require the smallest electric motor, with a torque of roughly $70 \mathrm{Nm}$. The (scaled) Moog pump on the other hand requires roughly $150 \mathrm{Nm}$ of torque to get the same amount of productivity.

Another difference between the different pumps is found when looking at the low speed operation in fig. 3. For most part of the operating range, roughly $85 \mathrm{Nm}$ is required to operate the scaled Rexroth pump at 200 bar. However, when a lower output flow rate is required, the torque requirement for this unit increases rapidly. This is caused by an increase in torque losses at low speeds, which will be discussed in sec. 6 .

Next to the difference in torque loss, fig. 2 also shows a difference in the minimum amount of flow that the pumps can output. For example, the Moog pump can deliver $0.70 \mathrm{lpm}$ at 200 bar, while the Marzocchi pump has a minimum of $5.66 \mathrm{lpm}$ at this pressure level. The inability to output low flow rates is caused by flow losses, and can lead to difficult control issues. This flow loss and its effects on the performance of EHAs in particular, will be discussed in sec. 7 .

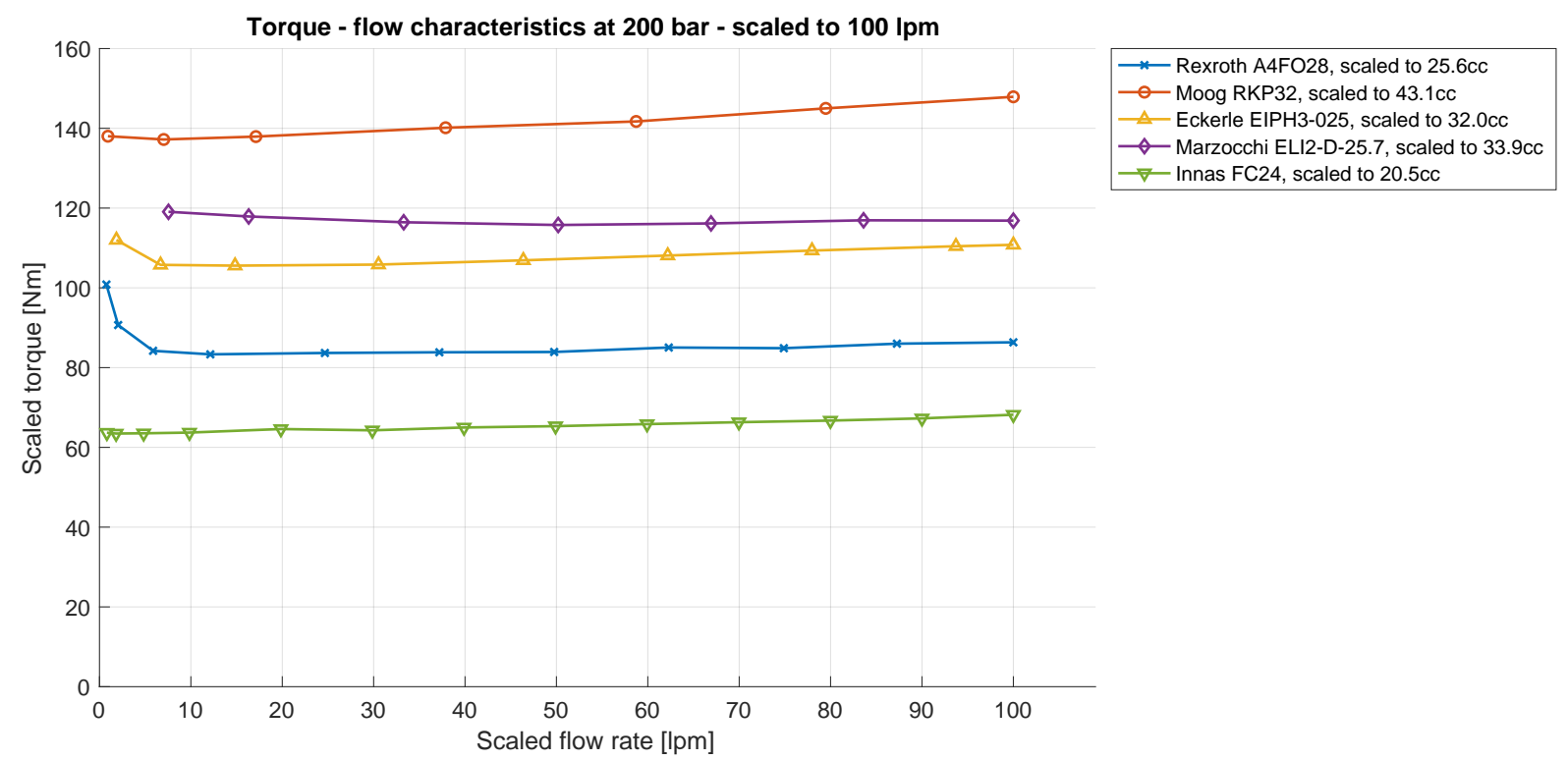

Figure 3: Torque as a function of the discharge flow rate at a discharge pressure of 200 bar, scaled to a maximum flow rate of $100 \mathrm{lpm}$.

\section{Efficiency}

Before looking at the individual torque and flow losses, we look at the efficiency of the different pumps. Since the goal of applying EHAs is to increase system efficiency, the pump efficiency is an important result of the highspeed measurements. Pumps are used to convert mechanical energy into hydraulic energy. In the case of EHAs, the electric motor is responsible for the mechanical power. Energy is therefore stored in bulky and expensive batteries. A higher efficiency primarily means smaller batteries can be used to get the same amount of work done.

Furthermore, when a pump has poor efficiency, the lost energy will increase the temperature of the oil. Managing the oil temperature will likely involve large cooling solutions that also require power from the battery pack. In other words, using a pump with higher efficiency also reduces the amount of energy needed to cool the oil in the system.

\subsection{Definition}

The rate at which mechanical power is converted to hydraulic power is defined as the efficiency, and can be calculated using eq. (2).

$$
\eta=\frac{P_{h y d}}{P_{\text {mech }}}
$$

In which $\eta$ is the efficiency of the pump, and $P_{\text {mech }}$ and $P_{h y d}$ the measured mechanical and hydraulic power, respectively. According to [12], the mechanical power, $P_{\text {mech }}$, and hydraulic power, $P_{\text {hyd }}$, are calculated using eq. (3) and (4).

$$
P_{\text {mech }}=T \omega
$$




$$
P_{\text {hyd }}=p_{2} Q_{2} a_{P}-p_{1} Q_{1}, \quad \text { with } a_{P}=1+\frac{p_{2}}{2 K_{s}}
$$

In which $T$ is the measured torque, $\omega$ the rotational speed, $p_{2}$ and $Q_{2}$ the pressure and flow rate at the high-pressure side of the device, and $p_{1}$ and $Q_{1}$ the pressure and flow rate at the low-pressure side. Furthermore, $a_{P}$ is a correction factor to account for the compression energy in high pressure oil flow, with $K_{s}$ the isentropic bulk modulus of the used oil. While traditional methods for calculating the hydraulic power ignore the compressibility effects captured in $a_{P}$, authors of several recent publications have concluded that these effects should be included when calculating the efficiency [12-14].

\subsection{Results}

The overall efficiency of all of the pumps was calculated using eq. (2). Figure 4 shows the results for different shaft speeds at an operating pressure of 200 bar. At low operating speeds, pumps are often unable to reach the required pressure level. In these cases, a second pump was used to ensure a correct circuit pressure. Since this second pump adds hydraulic energy to the system, eq. (4) no longer holds (i.e. a larger flow rate $Q_{2}$ will be measured). Therefore, it is not possible to determine the efficiency in these situations.

For all of the pumps, the efficiency in fig. 4 shows the same trend for an increasing shaft speed. At low operating speeds, the efficiency is low. As the machine starts rotating faster, the efficiency increases rapidly, until a maximum is reached somewhere between 1000 and $2000 \mathrm{rpm}$. As the shaft speed increases further, the efficiency decreases at a slower rate.

At this particular pressure level, the highest peak efficiency of almost 0.96 was realized by the Innas pump at $1000 \mathrm{rpm}$, while the Moog pump had the lowest peak efficiency of 0.87 at $1500 \mathrm{rpm}$. The other three pumps show very similar results to one another, all with a peak efficiency of 0.92 at $1500 \mathrm{rpm}$.

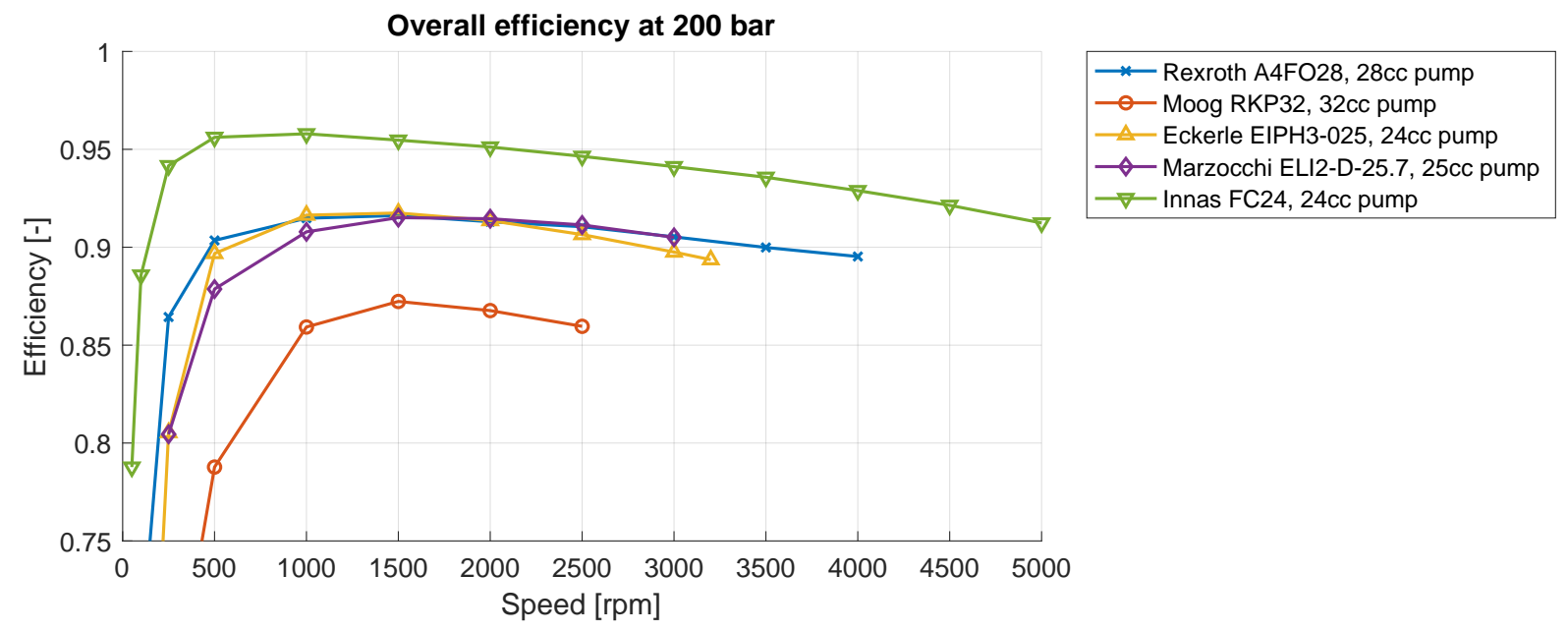

Figure 4: Comparison between the measured efficiency for all of the pumps at 200 bar.

\section{Torque loss}

Given the displacement size of a pump, it is possible to determine the torque that should theoretically be required to generate a certain amount of hydraulic power. However, since there is no such thing as a perfect pump, more torque will be required. Friction between moving parts, throttle losses due to limited flow areas, and improper commutation between the supply and discharge side, among other things, are all causes of torque loss inside of a pump. In the case of EHAs, higher torque loss means that a larger electric motor is needed to get the same amount of work done. Additionally, torque loss is a large contributor to the increase in oil temperature mentioned before.

At low operating speeds, coulomb friction greatly increases the amount of friction and resulting wear of the moving components in a pump. For this reason, classical valve controlled systems typically keep a pump rotating above a certain minimum speed. Closing a control valve will reduce the load velocity to zero. In speed controlled EHAs on the other hand, the pump will have to stop each time the load has to stop moving. To analyse the performance of the devices during starting and stopping, low-speed tests have been conducted. 


\subsection{Definition}

The torque loss of a positive displacement machine can be defined as the difference between the measured torque $T$, and the theoretical torque $T_{t h}$. According to [12], the theoretical torque can be calculated using eq. (5).

$$
T_{t h}=\frac{\Delta p V_{g}}{2 \pi} a_{T}, \quad \text { with } a_{T}=1-\left(\frac{1}{2}+r_{V}\right) \frac{\Delta p}{K_{s}}
$$

In which $\Delta p$ is the pressure difference over the device $\left(p_{2}-p_{1}\right)$, and $V_{g}$ is the derived displacement volume of the device as shown in tab. 1. Similar to the calculation of the efficiency, $a_{T}$ is a correction factor to account for the compressibility of the oil. This correction factor can be determined using the volume ratio $r_{V}$ (eq. (1), tab. 1). To be able to compare the torque loss of pumps of different sizes, the torque loss will be normalized by comparing it to the theoretical torque.

$$
\hat{T}_{\text {loss }}=\frac{T-T_{t h}}{T_{t h}}
$$

From eq. (6), the normalized torque loss can be seen as the additional amount of torque required to operate the pump, relative to the theoretical torque.

\subsection{Torque loss during normal operation}

The normalized torque loss of the five devices at an operating pressure of 200 bar is shown in fig. 5. In this figure, the same graph is shown on both a linear (left plot) and a logarithmic scale (right plot). The linear scaled plot mainly shows the losses at normal operating conditions, while the logarithmic plot provides some insight into the losses during low-speed and start-stop operation.

The logarithmic plot in fig. 5 shows that for a single device, for example the Moog pump, the torque loss is more or less constant at speeds up to $1 \mathrm{rpm}$. Between 1 and $250 \mathrm{rpm}$, the torque loss quickly decreases as the speed increases. At $250 \mathrm{rpm}$ the pump reaches a minimum torque loss, which is the lowest of the pumps measured here. For speeds above $250 \mathrm{rpm}$, the torque loss increases again. This trend is similar for most of the devices that were benchmarked and is in accordance with the Stribeck curve. The three sections describe the transition from coulomb friction (boundary lubrication), to mixed friction, and viscous friction (hydrodynamic lubrication), respectively.

At this pressure level, the five pumps show some differences with respect to each other. Overall, it can be found that the Innas pump has the lowest torque loss, especially in the low speed range. This can be explained by the fact that this is a floating cup type pump, which has almost no contact between the piston and the cylinder, and thus very little coulomb friction. In the viscous friction section, the torque loss in the Rexroth, the Eckerle, and the Innas units increase at roughly the same rate. The torque loss for the Moog pump increases at a faster rate, while the torque loss of the Marzocchi seems relatively constant at higher operating speeds.
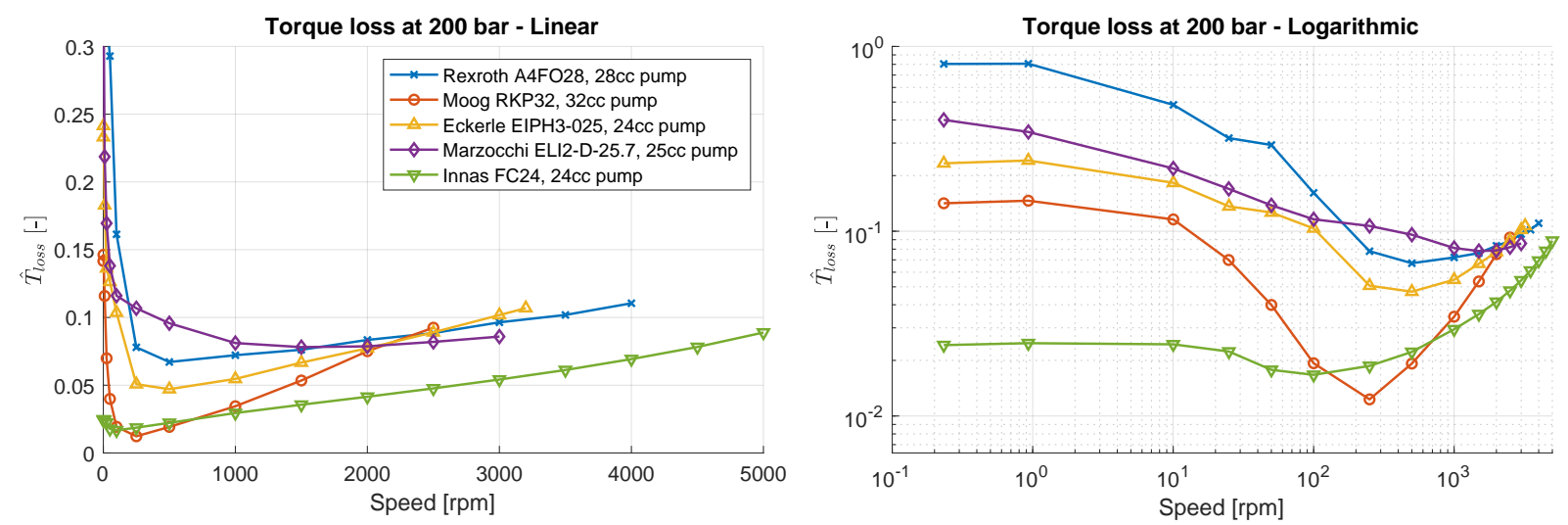

Figure 5: Comparison between the normalized torque losses for all of the devices at 200 bar.

\subsection{Torque loss during low-speed operation}

As mentioned before, the torque loss during measurements below $1 \mathrm{rpm}$ is more or less constant, as it is mainly caused by coulomb friction. At these low speeds, the torque loss can be seen as the amount of breakaway torque that is needed (additionally to the torque required for operation) to start the pump from standstill, while the system is already pressurized. The results shown in fig. 5 show average values of the torque loss. However, at these low operating speeds there is a significant difference in torque loss between different angular positions of the shaft. 
Figure 6 shows the torque loss, with respect to the angular position of the shaft, at a speed of $0.931 \mathrm{rpm}$ and a discharge pressure of 200 bar. This figure shows reoccurring patterns caused by the limited number of pistons per device. The remaining variations between the individual piston patterns are caused by small differences in the tribological interfaces. These patterns are very reproducible, as is shown in the full measurement report [8].

Figure 6 shows that the Rexroth, on average, has a normalized torque loss of roughly 0.8 . However, depending on the position of the shaft, this can be anywhere between 0.7 and 0.9 . This means that almost double the amount of theoretical torque is required to breakaway. The other pumps require less additional torque, with the Innas pump requiring only a maximum of 0.02 . From this figure, it becomes clear that not all of the tested pumps will be suitable for the stop-and-go kind of operation that is very common in several applications of EHAs.

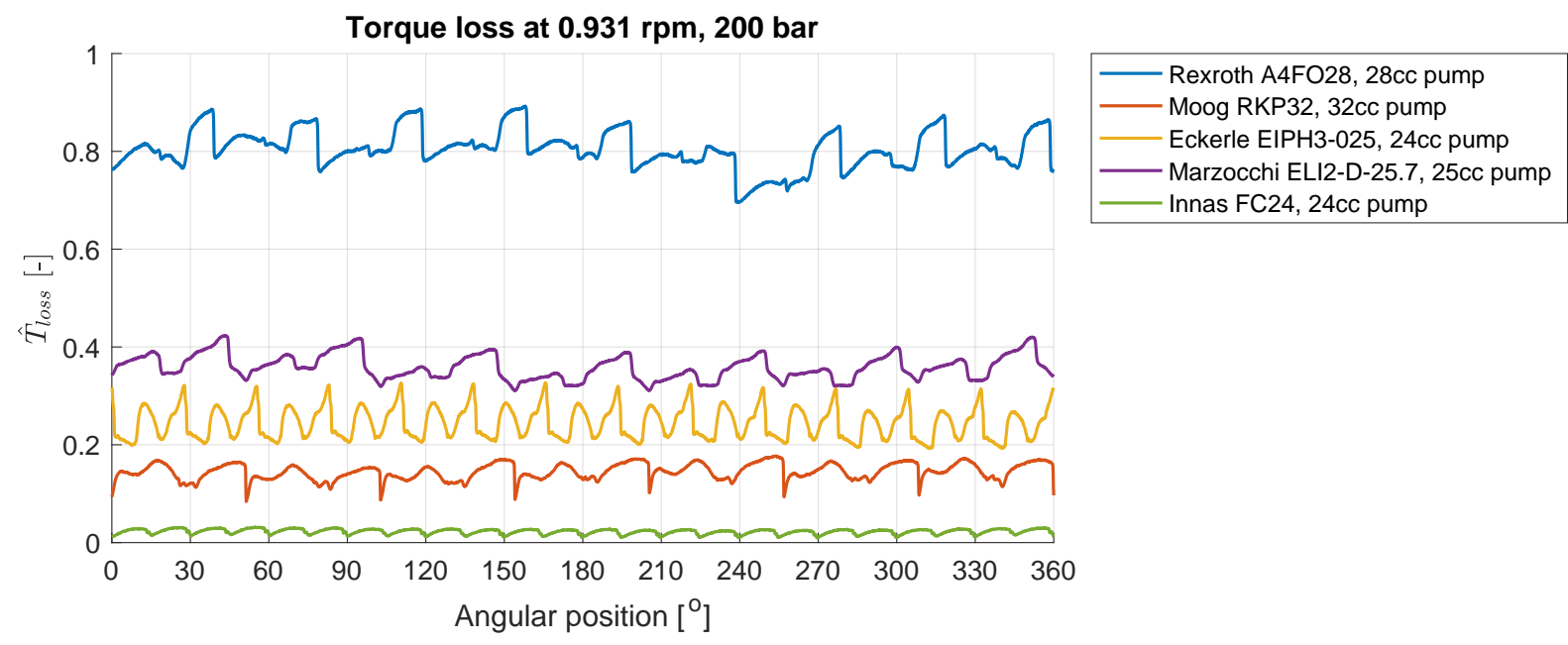

Figure 6: Torque loss as a function of the angular position for different pumps, at pressure 200 bar, speed $0.931 \mathrm{rpm}$.

\section{Flow loss}

Next to torque losses, hydraulic devices also experience flow losses. Based on the size of the pump, a certain flow rate is to be expected. However, since the moving parts inside a pump have a gap between them (albeit very small), oil will leak as soon as a pressure difference is present. Since flow occurs from high to low pressure volumes, the total flow loss will be a combination of several gaps.

First and foremost, oil can flow from the rotary group into the case. When a case drain line is available, this flow is directed back to the tank and can thus be measured. Most of this external leakage flow will come from the high-pressure side of the pump, since there is a large pressure difference between the pressure at the discharge port and the case pressure. However, since the case pressure is lower than the supply pressure, there will also be some leaked flow rate from the low-pressure side. Secondly, oil can also flow from the discharge side of the pump back into the supply side.

In case of EHAs, a pump with little to no flow loss is a very predictable device. Generally, this means that the control of such a device is fairly simple. In such a system, any change made to the speed of the electro-motor will result in a proportional change in velocity at the load. However, pumps often struggle to reach the desired pressure level at low operating speeds since all flow that the pump generates is lost before reaching the outlet port. In practice, this means that the control of the EHA has a dead-band. In the low speed region, a rotation of the electric motor does not result in movement of the load, leading to a non-linear system response. This undesirable behaviour will occur each time the load velocity switches direction, or the load has to stop and start moving again.

\subsection{Definition}

The flow loss of a positive displacement machine can be defined as the difference between the measured flow rate at the high pressure side $Q_{2}$, and the theoretical flow rate $Q_{2, t h}$. The theoretical flow rate can be calculated using eq. (7).

$$
Q_{2, t h}=\frac{\omega V_{g}}{2 \pi} a_{Q}, \quad \text { with } a_{Q}=1-\left(1+r_{V}\right) \frac{\Delta p}{K_{s}}
$$

As was the case with hydraulic power and torque, correction factor $a_{Q}$ is required to account for compressibility effects in the theoretical flow rate. To be able to compare the flow loss of pumps of different sizes, the flow loss 
will be normalized by comparing it to the theoretical flow.

$$
\hat{Q}_{2, l o s s}=\frac{Q_{2, t h}-Q_{2}}{Q_{2, t h}}
$$

\subsection{Overall flow loss}

The normalized flow loss of all the devices at an operating pressure of 200 bar is shown in fig. 7. The left figure shows that the flow loss at speeds above $1000 \mathrm{rpm}$ is less than 0.05 for most of the devices. Additionally, at higher speeds, the flow loss is relatively constant for these devices, which is beneficial for the control of EHAs. At speeds below $1000 \mathrm{rpm}$, the flow loss rapidly increases as is illustrated more clearly in the right plot of fig. 7.

In the right plot of fig. 7, we see that the minimum speed at which the flow loss is measured is different for the different pumps. For example, the minimum speed of Marzocchi pump is $250 \mathrm{rpm}$, while the minimum speed of the Rexroth pump is $50 \mathrm{rpm}$. Most manufacturers will address that their pump should be operated above a certain minimum speed. In an effective EHA however, the pump should be able to operated at near zero speeds. To this end, the minimum speeds in fig. 7 correspond to the ability of the pump to reach the desired pressure level (200 bar in this case).
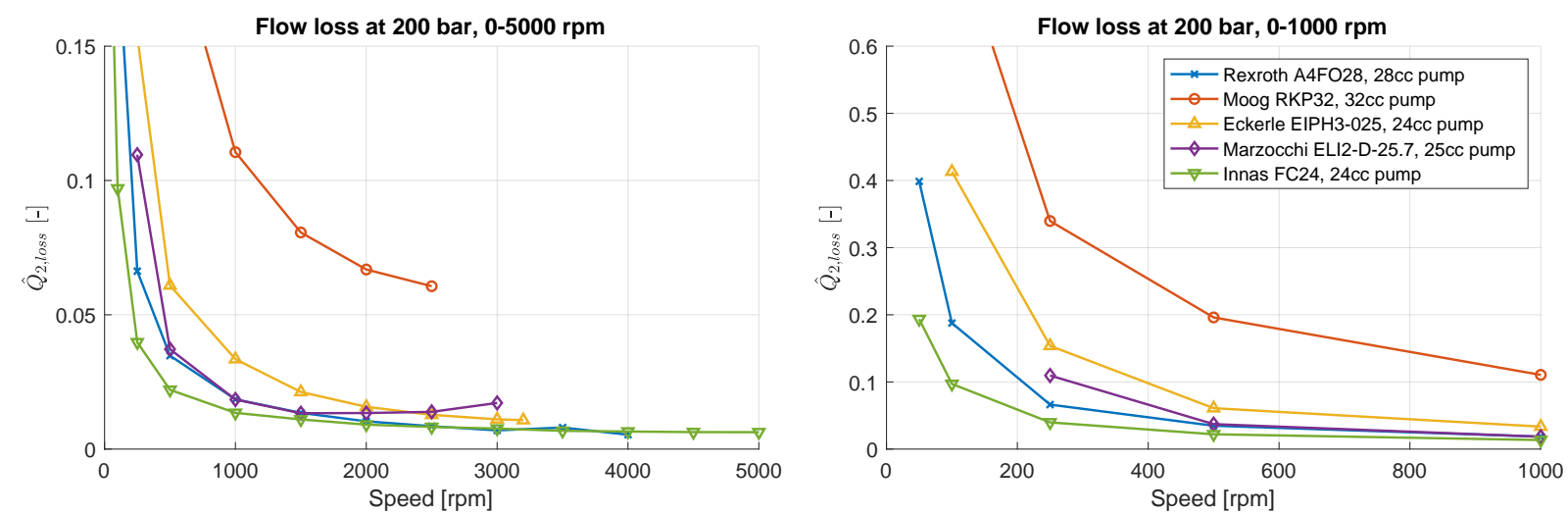

Figure 7: Comparison between the normalized flow losses for all of the devices at 200 bar.

\subsection{External leakage}

During the benchmark measurements, the external leakage from the rotary group to the housing of the devices is measured using a flow sensor. This flow rate is used to determine the flow rate at the low-pressure side of the device, which is standard practice [11]. The external leakage of three of the pumps at an operating pressure of 200 bar is shown in fig. 8. In the case of the two gear pumps, there is no external leakage port, so all flow loss will occur internally.

First and foremost, fig. 8 shows that the Moog pump has significantly more external leakage than the Rexroth and the Innas pump. This is likely caused by the different working principles (radial vs. axial), and the corresponding

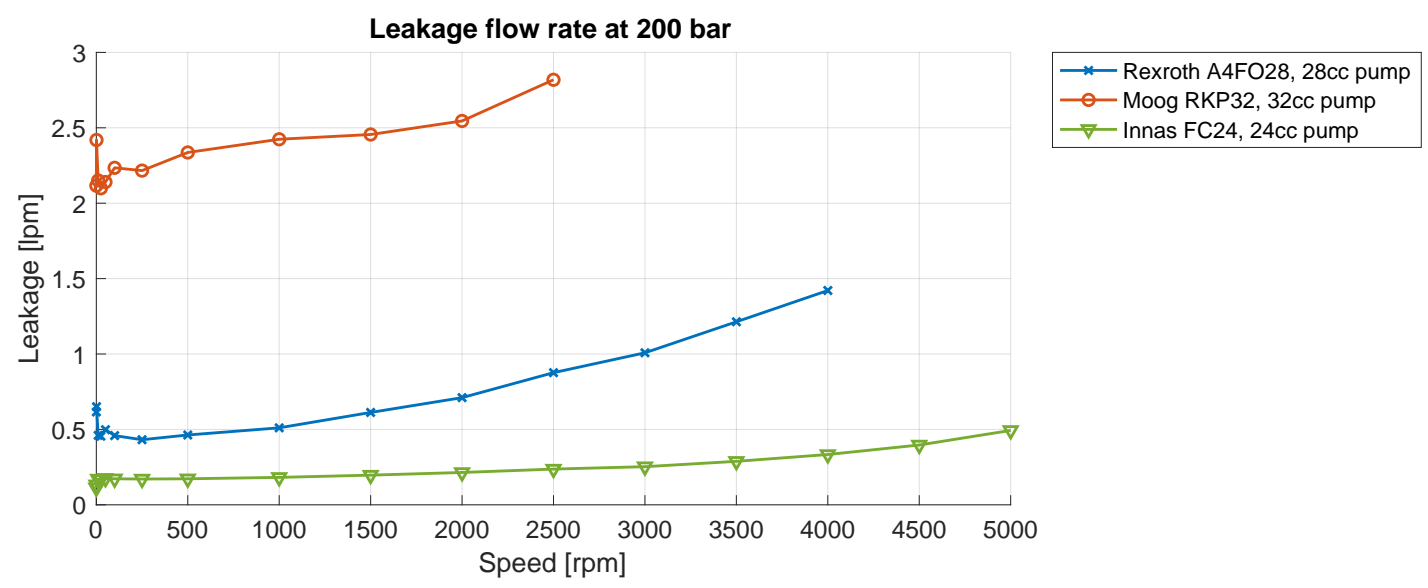

Figure 8: Comparison between the measured leakage flow rate for all of the device at 200 bar. 
sensitivity to manufacturing tolerances. For the two axial units, it can be found that the leakage flow only slightly increases at the lower operating speeds. At larger operating speeds, the leakage increases for these devices. This could be the result of barrel tipping [15].

\section{Conclusion}

In electro-hydraulic actuators (EHAs), the integrated combination between electric motors and hydraulic pumps sets very different requirements for the hydraulic pump than in a traditional, valve-controlled circuit. While a lot of research is being conducted about the control, and auxiliary components required for EHAs, little to no information is available on the performance of the actual pumps. Therefore, five different pumps were measured on the Innas test bench. The main focus during the analysis of the results has been on the application of these pumps in EHAs.

The results have shown that it is difficult for many of the traditional pumps to meet requirements related to the use in EHAs. First of all, the maximum rotational speeds has been shown to be a limiting factor. Pumps that have a relatively low maximum speed, need to be larger in order to output the same amount of flow. This directly translates to a larger electric motor for the same output. For example, it was found that some pumps will require an electric motor that is roughly twice the size of a motor required for other pumps, while the output flow rate is the same.

On the other side of the range of operation, the pumps were tested during very low speed conditions. Since the load in an EHA is directly controlled by the speed of the pump, the pump will often be operated around zero speed. It was found that pumps can have very large amounts of torque losses at starting speeds, which will also increase the size of the required electric motor. Additionally, at these starting speeds, large amounts of flow losses result in dead-bands in the control strategies for EHAs, leading to non-linear system response.

\section{Nomenclature}

\begin{tabular}{lll}
\hline Designation & Denotation & Unit \\
\hline$\Delta p$ & Pressure difference over the device $\left(p_{2}-p_{1}\right)$ & $\mathrm{Pa}$ \\
$\eta$ & Efficiency & - \\
$\omega$ & Measured rotational speed & $\mathrm{rad} / \mathrm{s}$ \\
$a_{P}$ & Compressibility correction factor for hydraulic power & - \\
$a_{Q}$ & Compressibility correction factor for flow rate & - \\
$a_{T}$ & Compressibility correction factor for torque loss & - \\
$K_{s}$ & Isentropic bulk modulus (constant, $\left.K_{s}=1.76 \mathrm{e} 9\right)$ & $\mathrm{Pa}$ \\
$P_{h y d}$ & Hydraulic power & $\mathrm{W}$ \\
$P_{\text {mech }}$ & Mechanical power & $\mathrm{W}$ \\
$p$ & Pressure & $\mathrm{Pa}$ \\
$Q$ & Flow rate & $\mathrm{m}^{3} / \mathrm{s}$ \\
$\hat{Q}_{2, l o s s}$ & Normalized flow loss & - \\
$Q_{2, t h}$ & Theoretical discharge flow rate & $\mathrm{m}^{3} / \mathrm{s}$ \\
$r_{V}$ & Ratio between dead volume and displacement volume per piston $($ or tooth) & - \\
$T$ & Measured shaft torque & $\mathrm{Nm}$ \\
$\hat{T}_{l o s s}$ & Normalized torque loss & - \\
$T_{t h}$ & Theoretical torque & $\mathrm{Nm}$ \\
$V_{g}$ & Displacement volume per revolution & $\mathrm{m}^{3}$ \\
$V_{\text {min }}$ & Dead volume per piston & $\mathrm{m}^{3}$ \\
$z$ & Number of pistons or driving teeth & - \\
\hline & & \\
\hline Subscript & Port on device & \\
\hline 1 & Low-pressure side (supply) & \\
2 & High-pressure side (discharge) & \\
\hline
\end{tabular}

\section{References}

[1] European Commission. Non-road mobile machinery emissions. https://ec.europa.eu/growth/ sectors/automotive/environment-protection/non-road-mobile-machinery_en. Accessed: 2901-2021. 
[2] Ahmed Imam, Moosa Rafiq, Ehsan Jalayeri, and Nariman Sepehri. Design, implementation and evaluation of a pump-controlled circuit for single rod actuators. In Actuators, volume 6, page 10. Multidisciplinary Digital Publishing Institute, 2017.

[3] Lasse Schmidt, Søren Ketelsen, Morten Helms Brask, and Kasper Aastrup Mortensen. A class of energy efficient self-contained electro-hydraulic drives with self-locking capability. Energies, 12(10):1866, 2019.

[4] Søren Ketelsen, Giacomo Kolks, Torben Ole Andersen, Lasse Schmidt, and Jürgen Weber. Bootstrap reservoir concept for electro-hydraulic compact drives. In 12th International Fluid Power Conference, 2020.

[5] Haigang Ding and Jiyun Zhao. A new method of improving low-speed performance of variable speed hydraulic systems: by leaking parallel valve control. Advances in Mechanical Engineering, 6:967373, 2014.

[6] Shaoyang Qu, David Fassbender, Andrea Vacca, Enrique Busquets, and Uwe Neumann. A closed circuit electro-hydraulic actuator with energy recuperation capability. In 12th International Fluid Power Conference, 2020.

[7] Martin Inderelst, David Prust, and Michael Siegmund. Electro-hydraulic swot-analysis on electro-hydraulic drives in construction machinery. In 12th International Fluid Power Conference, 2020.

[8] Innas BV. Performance of hydrostatic machines; extensive measurement report. https: //www . innas . com/ assets/performance-of-hydrostatic-machines .pdf. Accessed: 29-01-2021.

[9] Gijsbert Toet, Jack Johnson, John Montague, Ken Torres, and José Garcia-Bravo. The determination of the theoretical stroke volume of hydrostatic positive displacement pumps and motors from volumetric measurements. Energies, 12(3):415, 2019.

[10] Peter Achten, Jeroen Potma, and Sjoerd Eggenkamp. A new hydraulic pump and motor test bench for extremely low operating speeds. In ASME/BATH 2017 Symposium on Fluid Power and Motion Control. American Society of Mechanical Engineers Digital Collection, 2017.

[11] ISO4409:2019. Hydraulic fluid power, positive displacement pumps, motors and integral transmissions; Methods of testing and presenting basic steady state performance. International Organization for Standardization, 2019.

[12] Peter Achten, Robin Mommers, Takao Nishiumi, Hubertus Murrenhoff, Nariman Sepehri, Kim Stelson, JanOve Palmberg, and Katharina Schmitz. Measuring the losses of hydrostatic pumps and motors; a critcal review of iso4409:2007. In BATH/ASME 2019 Symposium on Fluid Power and Motion Control. American Society of Mechanical Engineers, 2019.

[13] Christopher Williamson and Noah Manring. A more accurate definition of mechanical and volumetric efficiencies for Digital Displacement $\AA$ pumps. In BATH/ASME 2019 Symposium on Fluid Power and Motion Control. American Society of Mechanical Engineers, 2019.

[14] Perry Y Li and Jonathan Barkei. Hydraulic effort and the efficiencies of pumps and motors with compressible fluid. In BATH/ASME 2020 Symposium on Fluid Power and Motion Control. American Society of Mechanical Engineers, 2020.

[15] Peter Achten and Sjoerd Eggenkamp. Barrel tipping in axial piston pumps and motors. In Proceedings of 15th Scandinavian International Conference on Fluid Power, June 7-9, 2017, Linköping, Sweden, number 144, pages 381-391. Linköping University Electronic Press, 2017. 